\title{
Correction to: Deformation modeling based on mechanical properties of liver tissue for virtual surgical simulation
}

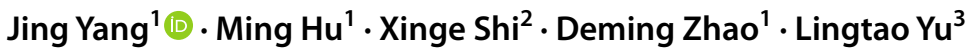 \\ Published online: 17 April 2021 \\ (c) CARS 2021

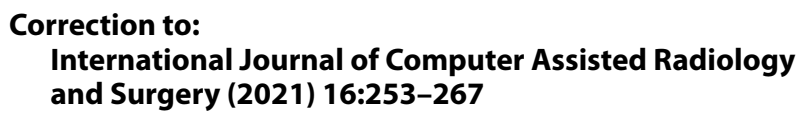

The original version of this article unfortunately contained a mistake. Article title is wrong

The correct title should be

Deformation modeling based on mechanical properties of liver tissue for virtual surgical simulation

Publisher's Note Springer Nature remains neutral with regard to jurisdictional claims in published maps and institutional affiliations.

The original article can be found online at https://doi.org/10.1007/ s11548-020-02297-7.

Ming $\mathrm{Hu}$

huming@zstu.edu.cn

1 Faculty of Mechanical Engineering and Automation, Zhejiang Sci-Tech University, Hangzhou, Zhejiang Province, China

2 Henan Provincial People's Hospital, Zhengzhou, Henan Province, China

3 College of Mechanical and Electrical Engineering, Harbin Engineering University, Harbin, Heilongjiang Province, China 